\author{
DOI: 10.12731/2658-6649-2019-11-3-54-68 \\ УДК 616.248
}

\title{
БРОНХИАЛЬНАЯ АСТМА: МОНИТОРИРОВАНИЕ КАЧЕСТВА ДИСПАНСЕРИЗАЦИИ БОЛЬНЫХ ВРАЧОМ АЛЛЕРГОЛОГОМ-ИММУНОЛОГОМ
}

\author{
Ганцева Х.Х., Ханова А.К., Явгильдина А.М.
}

Статья посвящена мониторированию качества диспанцеризацчи больных с бронхиальной астмой.

Цель. Разработка объективного длительного мониторирования пацчиентов, оченка качества проведения образовательных программ, страдающих бронхиальной астмой в процессе диспансерного наблюдения.

Материалы и методы. Для комплексной оиенки динамического этапного мониторирования пациентов с диагнозом «Бронхиальная астма» использованы анкеты из трех блоков вопросов, а также анализ оценок в рамках клинических примеров с иеленаправленным повторным анкетированием пацичентов. Первый этап оченки проводился перед началом реализации образовательной программы. Второй этап оценки - после завершения учебного прочесса по той же анкете, с целью выявления конечного уровня их знаний для коррекции процесса обучения при реализации последуюшей ичепочки образовательных программ. Третий этап проводится через 1 год, на повторном тестировании и для обеспечения дифференцированной тактики дальнейшего ведения пацчиентов.

Результаты. На клиническом примере пациентки с бронхиальной астмой проведен расчет результатов анкетирования на первом, втором и третьем этапах исследования у пациента с исходно низким уровнем подготовленности по всем трем блокам знаний, умении, оценки качества жизни, с достижсением высокого уровня компетентности в результате курса обучения, пациентка признана не нуждающейся в повторном обучении, и ей было предложено продолжение только диспансерного наблюдения.

Заключение. Технический результат при использовании методики улучшение уровня качества жизни пациентов с бронхиальной астмой. Поэтапное анкетирование пациентов по вылвлению уровня их информированности позволяет выстрочть стройную дифференцированную си- 
стему их обучения в "Астме-школе», которая не осуществима другими способами диагностики.

Ключевые слова: бронхиальная астма; астма-икола; качество обучения пациента; трудовые функции врача аллерголога-иммунолога.

\title{
BRONCHIAL ASTHMA: MONITORING THE QUALITY OF DISPENSIONIZATION OF PATIENTS BY THE ALLEROLOGIST-IMMUNOLOGY
}

\author{
Gantseva Kh.Kh., Khanova A.K., Yavgildina A.M.
}

The article is devoted to monitoring the quality of medical examination of patients with asthma.

Goal. Development of objective long-term monitoring of patients, assessment of the quality of educational programs suffering from bronchial asthma during the follow-up.

Materials and methods. For a comprehensive assessment of the dynamic step-by-step monitoring of patients with a diagnosis of bronchial asthma, questionnaires from three blocks of questions were used, as well as analysis of assessments in the framework of clinical examples with targeted repeated questioning of patients. The first stage of the assessment was carried out before the start of the educational program. The second stage of assessment-after the completion of the educational process on the same questionnaire, in order to identify the final level of their knowledge to correct the learning process during the implementation of the subsequent chain of educational programs. The third stage is carried out after 1 year, on re-testing and to ensure differentiated tactics for further management of patients.

Results. On the clinical example of a patient with bronchial asthma, the results of the questionnaire were calculated at the first, second and third stages of the study in a patient with an initially low level of preparedness for all three blocks of knowledge, skills, assessing the quality of life, and achieving a high level of competence as a result of a training course, the patient was recognized not in need of re-training, and she was offered the continuation of only dispensary observation.

Conclusion. The technical result when using the technique is to improve the quality of life of patients with bronchial asthma. Phased questioning of patients 
to identify their level of awareness allows you to build a harmonious differentiated system of their education in "Asthma-school", which is not feasible by other diagnostic methods.

Keywords: bronchial asthma; asthma-school; quality of patient education; labor functions of an allergist-immunologist.

\section{Актуальность}

Диспансерное наблюдение за состоянием здоровья пациентов, страдающих бронхиальной астмой (диспансеризация) требует от медицинского персонала динамического контроля за субъективными и объективными показателями их здоровья $[1,2]$. Установлено, что необходимость длительного многолетнего лечения бронхиальной астмы снижает приверженность пациентов к соблюдению саногенного поведения $[3,4,5]$. Кроме того, стремительное развитие новых биомедицинских технологий создает необходимость повторного прохождения пациентами всего курса обучения в школах для пациентов или избирательных тем занятий $[6,7]$. Это диктует необходимость создания системы мониторирования уровня информированности пациентов, качества владения практическими навыками и состоянием их здоровья.

В доступной нам литературе мы не нашли способа комплексного динамического этапного мониторирования уровня компетентности пациентов, обучающихся в «астма-школе» с целью оптимизации дальнейшей тактики амбулаторного ведения пациентов, что обусловлено отсутствием «обратной связи» между обучающим врачом и обучаемыми пациентами [8].

\section{Цель исследования}

Разработка объективного способа длительного мониторирования уровня информированности пациентов оценки качества проведения образовательных программ для пациентов, страдающих бронхиальной астмой в процессе диспансерного наблюдения

\section{Материалы и методы}

Для оценки комплексного динамического этапного мониторирования пациентов с диагнозом «Бронхиальная астма» использованы анкеты, состоящие из 3 блоков вопросов. Представлен клинический пример, продемонстрировавший этапы оценок.

В основе предлагаемой методической системы лежит целенаправленное повторное анкетирование пациентов и выпускников «Астма-школы» 
по выявлению уровня теоретических знаний, усвоенных практических навыков и умений, состояния здоровья с целью своевременного восполнения дефицита знаний и оказания своевременной медицинской помощи.

Для этого проводится анкетирование пациентов по анкете, состоящей из 3 блоков вопросов. Первый блок вопросов касается теоретических знаний, полученных в процессе обучения в «астма-школе», второй блок вопросов оценивает уровень приобретенных практических навыков и умений и третий блок вопросов уточняет динамику течения заболевания по объективизированным статистическим медицинским критериям.

Технический результат при использовании методики - улучшение уровня качества жизни больных бронхиальной астмой.

Первый этап оценки - вхождения в мониторинг проходит на базе лечебно-профилактического учреждения, в котором проводится «Астма-школа» (стационар, поликлиника, санаторий) перед началом реализации образовательной программы. Пациентам, приглашенным в «Астма-школу» предлагается ответить на вопросы, представленные в разработанной тематической анкете. Суммируют полученные баллы и при количестве баллов от 40 до 66 оценивают уровень знаний, навыков пациентов как низкий, 67-93 - как средний, 94-120 - как высокий.

Целью данного исследования является выявление исходного уровня знаний пациентов по основным вопросам образовательной программы, предназначенной для данной группы пациентов.

Пациенты, показавшие высокий и средний уровень информированности и владения практическими навыками с благоприятной динамикой течения заболевания, приглашаются на посещение тематических занятий «Астма-школы» по их выбору. В дальнейшем они находятся под диспансерным наблюдением и приглашаются для прохождения ежегодной диспансеризации. Кроме того, им оказывается специализированная медицинская помощь по обращаемости.

Пациенты, показавшие низкий уровень информированности и/или владения практическими навыками, приглашаются для обучения в «Астмашколу».

Второй этап оценки проводится после завершения учебного процесса. Процедура направлена на оценку эффективности реализации образовательной программы. С этой целью проводится повторное тестирование пациентов по той же анкете, с целью выявления конечного уровня их знаний. Это позволяет произвести необходимую коррекцию процесса обучения для реализации последующей цепочки образовательных программ. 
Пациенты, показавшие высокий и средний уровень информированности и владения практическими навыками с благоприятной динамикой течения заболевания, остаются под диспансерным наблюдением. При необходимости им оказывается специализированная медицинская помощь по обращаемости.

Пациенты, показавшие низкий уровень информированности и/или владения практическими навыками продолжают обучение в «Астма-школе» по индивидуальной программе либо выборочно посещают занятия для восполнения знаний и навыков, а в дальнейшем переходят в группу диспансерного наблюдения. Вместе с тем, им оказывается специализированная медицинская помощь по обращаемости.

Третий этап оценочных мероприятий проводится через год. Пациентов, прошедших обучение в «Астма-школе» приглашают на повторное тестирование по той же анкете с целью выявления остаточного уровня знаний по вопросам тематической образовательной программы. Анализ результатов опроса пациентов позволяет дифференцировать тактику дальнейшего ведения пациентов и произвести их отбор для повторного обучения с целью восстановления знаний, полученных на первом этапе обучения.

Пациенты, сохранившие высокий и средний уровень теоретических знаний, полученных в процессе обучения в «астма-школе», приобретенных практических навыков и умений и с благоприятной динамикой течения заболевания, остаются под диспансерным наблюдением. При необходимости им оказывается специализированная медицинская помощь по обращаемости.

Пациенты, показавшие низкий уровень остаточных знаний и/или владения практическими навыками приглашаются на повторное обучение в «Астма-школе» с целью закрепления знаний, полученных на первом этапе обучения, или продолжают обучение по индивидуальной программе.

Пациентам, показавшим низкий уровень качества жизни и отрицательную динамику течения заболевания по объективизированным статистическим медицинским критериям, через год после завершения курса обучения в «астма-школе» проводится врачебная экспертная оценка функционального состояния, оказывается индивидуальная специализированная медицинская помощь в амбулаторных или стационарных условиях, расширяются реабилитационные мероприятия, при необходимости пациент направляется на медико-социальную экспертизу в условиях МСЭК. Кроме 
того, пациент приглашается на повторное обучение в «Астма-школе» с целью восстановления знаний, навыков и умений или продолжает обучение по индивидуальной программе.

\section{Результаты исследования и их обсуждение}

Предлагаемый подход иллюстрируется следующим примером.

Клинический пример 1. Пациентка П., 44 лет, 3 месяца назад был установлен диагноз «бронхиальная астма». Прошла полный курс обучения в «Астма-школе» на базе муниципальной поликлиники.

1. Первый этап анкетирования провели перед началом реализации образовательной программы с целью выявления исходного уровня знаний, владения практическими навыками и умениями пациента по основным вопросам образовательной программы.

Ответы на вопросы первого блока показали следующий уровень знаний: незнание анатомического строения органов дыхания, физиологии дыхания (1 балл), хорошее знание собственных антропометрических показателей - роста, массы тела (3 балла), хорошее знание собственных показателей гемодинамики - пульса, уровня артериального давления (3 балла), удовлетворительное знание всех управляемых факторов риска формирования и обострения астмы (2 балла), удовлетворительное знание признаков обострения заболевания (2 балла), удовлетворительное знание принципов клинико-функционального самоконтроля за течением астмы (2 балла), удовлетворительное знание назначения таких приборов индивидуального пользования, как спейсер и пикфлоуметр (2 балла), удовлетворительное знание принципов элиминационной терапии заболевания (2 балла), удовлетворительное знание современных лекарственных препаратов и методов лечения бронхиальной астмы (2 балла), удовлетворительное знание ингаляционных устройств для лечения астмы (2 балла), удовлетворительное знание принципов здорового образа жизни (2 балла), удовлетворительное знание основ диетотерапии больного бронхиальной астмой (2 балла), не знание принципов дыхательной гимнастики и физкультуры для пациентов бронхиальной астмой, закаливания (1 балл), удовлетворительное знание основ общего массажа и массажа лица (2 балла).

Анкетирование по вопросам второго блока по уровню приобретенных практических навыков и умений показало отсутствие владения навыком по подсчету пульса (1 балл), отсутствие владения навыками по подсчету частоты дыхания (1 балл), неумение оценки состояния по системе цветовых «зон» (1 балла), отсутствие владения техникой пикфлоуметрии 
(1 балл), неумение интерпретации результатов диагностических процедур (1 балл), отсутствие способности пациента самостоятельно предотвращать приближающееся ухудшение в течении астмы (1 балл), отсутствие владения техникой ингаляций при использовании дозированных ингаляторов, спейсеров, небулайзеров (1 балл), отсутствие дневника самонаблюдения (1 балл), отсутствие навыков по дыхательным методикам по методу биологически обратной связи (1 балл), отсутствие навыка по волевому управлению дыханием (1 балл), отсутствие владения элементами самомассажа биологически активных точек для активного использования в приступном периоде наряду с дыхательной гимнастикой (1 балл), отсутствие владения навыками мышечной релаксации (1 балл), отсутствие владения элементами аутотренинга (1 балл), отсутствие владения психотерапевтическими приемами (1 балл), отсутствие навыков по лечебной физкультуре (1 балл), отсутствие навыков по составлению домашней аптечки (1 балл); удовлетворительное навыки саногенного поведения (2 балла).

Анкетирование по вопросам третьего блока по динамике течения заболевания согласно объективизированным статистическим медицинским критериям показало наличие редких приступов удушья (2 балла); отсутствие ночных приступы удушья (1 балл); 2 обострения (2 балла); 1 госпитализация (2 балла); более 14 дней временной нетрудоспособности (1 балл); 2 вызова бригады «скорой помощи» (2 балла), отсутствие группы инвалидности (3 балла); общее состояние без перемен (2 балла), средний уровень самооценки качества жизни (2 балла).

Суммируя полученные результаты, получено 62 балла. Таким образом, выявлен низкий уровень знаний пациента до проведения «астма-школы».

Второй этап анкетирования провели после завершения учебного процесса с целью оценки эффективности реализации образовательной программы.

Ответы на вопросы первого блока показали следующий уровень знаний: хорошее знание анатомического строения органов дыхания, физиологии дыхания (3 балла), хорошее знание собственных антропометрических показателей - роста, массы тела (3 балла), хорошее знание собственных показателей гемодинамики - пульса, уровня артериального давления (3 балла), хорошее знание всех управляемых факторов риска формирования и обострения астмы (3 балла), хорошее знание признаков обострения заболевания (3 балла), удовлетворительное знание принципов клиникофункционального самоконтроля за течением астмы (2 балла), хорошее знание назначения таких приборов индивидуального пользования, как 
спейсер и пикфлоуметр (3 балла), хорошее знание принципов элиминационной терапии заболевания (3 балла), хорошее знание современных лекарственных препаратов и методов лечения бронхиальной астмы (3 балла), хорошее знание ингаляционных устройств для лечения астмы (3 балла), хорошее знание принципов здорового образа жизни (3 балла), хорошее знание основ диетотерапии больного бронхиальной астмой (3 балла), хорошее знание принципов дыхательной гимнастики и физкультуры для больных бронхиальной астмой, закаливания (3 балла), хорошее знание основ общего массажа и массажа лица (3 балла).

Анкетирование по вопросам второго блока по уровню приобретенных практических навыков и умений показало хорошее владение навыком по подсчету пульса (3 балла), хорошее владение навыками по подсчету частоты дыхания (3 балла), удовлетворительный уровень обучения оценки состояния по системе цветовых «зон» (2 балла), хорошее владение техникой пикфлоуметрии (3 балла), хорошее умение интерпретации результатов диагностических процедур (3 балла), хорошая способность пациента самостоятельно предотвращать приближающееся ухудшение в течении астмы (3 балла), хорошее владение техникой ингаляций при использовании дозированных ингаляторов, спейсеров, небулайзеров (3 балла), хороший уровень ведения дневника самонаблюдения (3 балла), хорошее владение навыками по дыхательным методикам по методу биологически обратной связи (3 балла), хорошее владение навыками по волевому управлению дыханием (3 балла), хорошее владение элементами самомассажа биологически активных точек для активного использования в приступном периоде наряду с дыхательной гимнастикой (3 балла), хорошее владение навыками мышечной релаксации (3 балла), хорошее владение элементами аутотренинга (3 балла), удовлетворительное владение психотерапевтическими приемами (2 балла), хорошие навыки по лечебной физкультуре (3 балла), хорошие навыки по составлению домашней аптечки (3 балла); хорошие навыки саногенного поведения (3 балла).

Анкетирование по вопросам третьего блока по динамике течения заболевания согласно объективизированным статистическим медицинским критериям показало наличие редких приступов удушья (2 балла); отсутствие ночных приступы удушья (3 балл); 2 обострения (2 балла); 1 госпитализация (2 балла); более 14 дней временной нетрудоспособности (1 балл); 2 вызова бригады «скорой помощи» (2 балла), отсутствие группы инвалидности (3 балла); общее состояние без перемен (2 балла), средний уровень самооценки качества жизни (2 балла). 
Суммируя полученные результаты, получено 114 баллов. Таким образом, выявлен высокий уровень знаний пациента сразу после проведения «астма-школы». Больная была поставлена на учет в третью группу диспансерного наблюдения. При необходимости ей оказывалась специализированная медицинская помощь по обращаемости.

Третий этап анкетирования был проведен через год с целью выявления остаточного уровня знаний по вопросам образовательной программы.

Ответы на вопросы первого блока показали следующий уровень знаний: удовлетворительное знание анатомического строения органов дыхания, физиологии дыхания (2 балла), хорошее знание собственных антропометрических показателей - роста, массы тела (3 балла), хорошее знание собственных показателей гемодинамики - пульса, уровня артериального давления (3 балла), хорошее знание всех управляемых факторов риска формирования и обострения астмы (3 балла), хорошее знание признаков обострения заболевания (3 балла), удовлетворительное знание принципов клинико-функционального самоконтроля за течением астмы (2 балла), хорошее знание назначения таких приборов индивидуального пользования, как спейсер и пикфлоуметр (3 балла), удовлетворительное знание принципов элиминационной терапии заболевания (2 балла), удовлетворительное знание современных лекарственных препаратов и методов лечения бронхиальной астмы (2 балла), удовлетворительное знание ингаляционных устройств для лечения астмы (2 балла), хорошее знание принципов здорового образа жизни (3 балла), хорошее знание основ диетотерапии больного бронхиальной астмой (3 балла), удовлетворительное знание принципов дыхательной гимнастики и физкультуры для больных бронхиальной астмой, закаливания (2 балла), хорошее знание основ общего массажа и массажа лица (3 балла).

Анкетирование по вопросам второго блока по уровню приобретенных практических навыков и умений показало хорошее владение навыком по подсчету пульса (3 балла), хорошее владение навыками по подсчету частоты дыхания (3 балла), удовлетворительный уровень обучения оценки состояния по системе цветовых «зон» (2 балла), удовлетворительное владение техникой пикфлоуметрии (2 балла), удовлетворительное умение интерпретации результатов диагностических процедур (2 балла), удовлетворительная способность пациента самостоятельно предотвращать приближающееся ухудшение в течении астмы (2 балла), удовлетворительное владение техникой ингаляций при 
использовании дозированных ингаляторов, спейсеров, небулайзеров (2 балла), отсутствие дневника самонаблюдения (1 балл), удовлетворительное владение навыками по дыхательным методикам по методу биологически обратной связи (2 балла), удовлетворительное владение навыками по волевому управлению дыханием (2 балла), удовлетворительное владение элементами самомассажа биологически активных точек для активного использования в приступном периоде наряду с дыхательной гимнастикой (1 балла), удовлетворительное владение навыками мышечной релаксации (2 балла), удовлетворительное владение элементами аутотренинга (2 балла), удовлетворительное владение психотерапевтическими приемами (2 балла), хорошие навыки по лечебной физкультуре (3 балла), удовлетворительное навыки по составлению домашней аптечки (2 балла); хорошие навыки саногенного поведения (3 балла).

Анкетирование по вопросам третьего блока по динамике течения заболевания согласно объективизированным статистическим медицинским критериям показало наличие редких приступов удушья (2 балла); отсутствие ночных приступы удушья (3 балла); 2 обострения (2 балла); отсутствие госпитализации (3 балла); более 14 дней временной нетрудоспособности (1 балл); 2 вызова бригады «скорой помощи» (2 балла), отсутствие группы инвалидности (3 балла); общее состояние без перемен (2 балла), средний уровень самооценки качества жизни (2 балла).

Суммируя полученные результаты, получено 93 балла, что позволяет оценить средний уровень компетентности пациента.

В связи с тем, что пациентка сохранила средний уровень теоретических знаний, полученных в процессе обучения в «астма-школе» год назад, приобретенных практических навыков, и имела благоприятную динамику течения заболевания, она не нуждалась в повторном обучении, но было предложено диспансерное наблюдение.

Проведенное изучение исходного уровня знаний у пациентов до начала обучения, конечного - после завершения цикла обучения, остаточного через 12 месяцев выявило значительное повышение и хорошую выживаемость уровня теоретических знаний, практических навыков и умений по основным аспектам медицинской, социальной, психологической и физической реабилитации бронхиальной астмы и показало высокую результативность обучения пациентов в «астма-школе».

Эффективность разработанного способа оценивалась в сравнении с 44 пациентами (сравнительная группа), обучающимися в «астма-школе» 
в традиционной форме. Разработанный способ мониторирования был применен у 50 пациентов (основная группа). Было отмечено достоверное снижение частоты госпитализаций, обращаемости в поликлинику по поводу обострений заболевания, сроков временной нетрудоспособности, количества вызовов бригады скорой помощи, улучшение качества жизни, отсутствовали случаи усиления группы инвалидности $(\mathrm{p}<0,05)$.

Применение разработанной методики мониторирования уровня компетентности больных, посещающих «астма-школу» позволяет оценить уровень информированности и владения практическими навыками и умениями, с последующим динамическим наблюдением за уровнем компетентности и качеством функционального состояния больных.

Авторами в доступной научно-медицинской литературе не обнаружено сведений о разработке и применении системы длительного этапного мониторирования уровня компетентности пациентов бронхиальной астмой с последующей дифференцированной тактикой ведения больных в зависимости от полученных результатов анкетирования.

Кроме оценки ближайших результатов лечения, для изучения эффективности комплексной фармакотерапии пациентов с образовательной программой, были использованы отдаленные результаты, для чего было проведено анкетирование пациентов до начала нашего исследования и через год наблюдения. Результаты были оценены по следующим показателям: заболеваемость интеркурентной патологией органов дыхания (на 100 обследованных), обращаемость в поликлинику по поводу основного и интеркурентных заболеваний (на 100 обследованных), обращаемость за экстренной медицинской помощью по поводу БА (на 100 обследованных), число госпитализаций по поводу БА (на 100 обследованных), число пациентов, получивших лекарственные средства (на 100 обследованных) и среднее количество наименований лекарственных препаратов на одного пациента.

Анализируя отдаленные результаты лечения важно подчеркнуть, что пациенты с БА, включенные во вторую группу (фармакотерапия совместно с образовательной программой) по сравнению в первой группой (без обучения в «Астме-школе») отметили значительное улучшение состояния здоровья, что характеризовалось снижением заболеваемости интеркурентной патологией органов дыхания $(5,5 \pm 3,1$ и $20,7 \pm 5,6, \mathrm{p}<0,02)$, обращаемости в поликлинику при ухудшении состояния здоровья $(10,9 \pm 4,2$ и $28,3 \pm 6,2$, $\mathrm{p}<0,02)$, уменьшением обращения больных за экстренной помощью в связи с БА $(3,6 \pm 2,5$ и $17,0 \pm 5,1, \mathrm{p}<0,02)$ и т.д. (табл. 1$)$. 
Таблица 1.

Отдаленные показатели эффективности лечения в сопровождении тематического образования у пациентов с БА (на 100 человек)

\begin{tabular}{|l|c|c|c|}
\hline \multicolumn{1}{|c|}{ Показатели } & $\begin{array}{c}\text { Первая } \\
\text { группа } \\
\text { п=53 }\end{array}$ & $\begin{array}{c}\text { Вторая группа } \\
\text { (в комплексе с } \\
\text { образователь- } \\
\text { ной програм } \\
\text { мой) п=55 }\end{array}$ & p \\
\hline $\begin{array}{l}\text { Заболеваемость интеркурентной } \\
\text { патологией органов дыхания }\end{array}$ & $20,7 \pm 5,6$ & $5,5 \pm 3,1$ & $<0,02$ \\
\hline $\begin{array}{l}\text { Обращаемость в поликлинику по поводу } \\
\text { основного и интеркурентных заболеваний }\end{array}$ & $28,3 \pm 6,2$ & $10,9 \pm 4,2$ & $<0,02$ \\
\hline $\begin{array}{l}\text { Обращаемость за экстренной } \\
\text { медицинской помощью по поводу БА }\end{array}$ & $17,0 \pm 5,1$ & $3,6 \pm 2,5$ & $<0,02$ \\
\hline Госпитализировано по поводу БА & $5,7 \pm 3,2$ & 0,0 & - \\
\hline $\begin{array}{l}\text { Число пациентов, получивших } \\
\text { лекарственные средства }\end{array}$ & $18,9 \pm 5,4$ & $3,6 \pm 2,5$ & $<0,02$ \\
\hline $\begin{array}{l}\text { Среднее количество наименований лекар- } \\
\text { ственных препаратов на одного пациента }\end{array}$ & $2,5 \pm 0,5$ & $1,0 \pm 0,4$ & $<0,01$ \\
\hline
\end{tabular}

Что касается группы больных с фармакотерапевтическим и образовательным сопровождением, то полученные данные свидетельствуют о том, что существенно улучшились все анализируемые показатели (табл. 1).

Таким образом, доказана высокая эффективность образовательной программы в лечении пациентов и улучшении их качества жизни. Образовательные тематические программы для пациентов с БА должны стать неотъемлемой частью лечения в комплексном ведении пациентов с БА. Совершенствование инструментов контроля за качеством образовательных мероприятий позволит вести целевой поиск методических педагогических приемов.

\section{Выводы}

Использование разработанной системы диагностических мероприятий на базе лечебно-профилактического учреждения, в котором проводится «Астма-школа» перед началом реализации образовательной программы направлена на выявление исходного уровня знаний пациентов по основным вопросам образовательной программы, предназначенной для данной группы пациентов. Повторное анкетирование пациентов по той же анкете сразу после завершения учебного процесса проводится 
с целью выявления конечного уровня знаний пациентов и направлено на оценку эффективности реализации образовательной программы. Это позволяет произвести необходимую коррекцию процесса обучения при реализации последующих образовательных программ. Повторное тестирование пациентов через год проводится с целью выявления остаточного уровня знаний по вопросам образовательной программы и позволяет произвести отбор больных, которым необходимо пройти повторное обучение с целью закрепления знаний, полученных на первом этапе обучения. Поэтапное анкетирование пациентов по выявлению уровня информированности позволяет выстроить стройную дифференцированную систему их обучения в «Астма-школе», которая неосуществима другими способами диагностики.

\section{Список литературы}

1. Национальная программа «Бронхиальная астма у детей. Стратегия лечения и профилактика». Второе издание. М.: Издательский дом «Русский врач». 2013. C. 87.

2. Хохлов А.Л., Глембицкая О.В., Лилеева Е.Г. Оценка приверженности к терапии и качества жизни у больных с бронхиальной астмой после внедрения обучающих программ // Проблемы стандартизации в здравоохранении. 2016. № 7-8. С. 13-18.

3. Глембицкая О.В. Клинико-экономическая эффективность обучающих программ для больных бронхиальной астмой // Новости здравоохранения. 2016. №1. C. 23-30.

4. Мицкевич С.Э. Бронхиальная астма у детей. Диагностика, клиника, лечение, профилактика: Учебное пособие. Челябинск: Издательство «Челябинская государственная медицинская академия». 2011. С. 36.

5. Грецов А.Г. «Астма-школа»: тренинг конструктивной жизни для подростков, больных бронхиальной астмой // Адаптивная физическая культура. 2014. № 4 (36). С. 38-44.

6. Белевский А.С. Тест контроля астмы - «новая игрушка» или важный инструмент // Атмосфера. Пульмонология и аллергология. 2016. №1. С. 33-34.

7. Гавришина Е. В. Фармакоэпидемиологическая оценка терапии, направленной на поддержание контроля бронхиальной астмы в условиях реальной амбулаторной практики. Автореферат диссертации на соискание ученой степени кандидата медицинских наук. Волгоград, 2012. 22 с.

8. Reddel H.K., Barnes D.J. Pharmacological strategies for self-management of asthma exacerbations // Eur. Respir. J. 2010. 28(1). P. 182-199. 


\section{References}

1. Natsional'naya programma «Bronkhial'naya astma u detey. Strategiya lecheniya i profilaktika» [National program "Bronchial asthma in children. Treatment Strategy and Prevention"]. M.: Publishing House "Russian Doctor". 2013. P. 87.

2. Khokhlov A.L., Glembitskaya O.V., Lileeva E.G. Otsenka priverzhennosti k terapii i kachestva zhizni u bol'nykh s bronkhial'noy astmoy posle vnedreniya obuchayushchikh program [Assessment of adherence to therapy and quality of life in patients with bronchial asthma after the introduction of training programs]. Problemy standartizatsii $v$ zdravookhranenii [Problems of standardization in healthcare]. 2016. No. 7-8. P. 13-18.

3. Glembitskaya O.V. Kliniko-ekonomicheskaya effektivnost' obuchayushchikh programm dlya bol'nykh bronkhial'noy astmoy [Clinical and economic effectiveness of training programs for patients with bronchial asthma]. Novosti zdravookhraneniya [Health News]. 2016. No. 1. P. 23-30.

4. Mitskevich S.E. Bronkhial'naya astma u detey. Diagnostika, klinika, lechenie, profilaktika [Bronchial asthma in children. Diagnosis, Clinic, Treatment, Prevention]. Chelyabinsk: Publishing House "Chelyabinsk State Medical Academy". 2011. P. 36.

5. Gretsov A.G. «Astma-shkola»: trening konstruktivnoy zhizni dlya podrostkov, bol'nykh bronkhial'noy astmoy ["Asthma-school": constructive life training for adolescents with bronchial asthma]. Adaptivnaya fizicheskaya kul tura [Adaptive physical education]. 2014. No. 4 (36). P. 38-44.

6. Belevskiy A.S. Test kontrolya astmy - «novaya igrushka» ili vazhnyy instrument [An asthma control test is a "new toy" or an important tool]. Atmosfera. Pul'monologiya i allergologiya [Atmosphere. Pulmonology and allergology]. 2016. No. 1. P. 33-34.

7. Gavrishina E.V. Farmakoepidemiologicheskaya otsenka terapii, napravlennoy na podderzhanie kontrolya bronkhial'noy astmy v usloviyakh real'noy ambulatornoy praktiki [Pharmacoepidemiological assessment of therapy aimed at maintaining control of bronchial asthma in real outpatient practice]. Abstract of dissertation for the degree of candidate of medical sciences. Volgograd, 2012. $22 \mathrm{p}$.

8. Reddel H.K., Barnes D.J. Pharmacological strategies for self-management of asthma exacerbations. Eur. Respir. J. 2010. 28(1). P. 182-199.

\section{ДАННЫЕ ОБ АВТОРАХ}

Ганцева Халида Ханафиевна, д.м.н., профессор, зав. кафедрой внутренних болезней

ФГБОУ ВО «Баикирский государственный медицинский университет» Министерства здравоохранения Российской Федерации 
ул. Ленина, 3, г. Уфа, Российская Федерацчия halida.ganceva@mail.ru

Ханова Айритта Каримовна, к.м.н., доцент кафедры внутренних болезней ФГБОУ ВО «Башкирский государственный медицинский университет» Министерства здравоохранения Российской Федерации ул. Ленина, 3, г. Уфа, Российская Федерации

Явгильдина Альфия Мустамировна, к.м.н., доцент кафедры внутренних болезней

ФГБОУ ВО «Башкирский государственный медицинский университет» Министерства здравоохранения Российской Федерации ул. Ленина, 3, г. Уфа, Российская Федераџчия

\section{DATA ABOUT THE AUTHORS}

Gantseva Khalida Khanafievna, Doctor of Medical Sciences, Professor, Head Department of Internal Medicine Bashkir State Medical University

3, Lenin st., Ufa, Russian Federation halida.ganceva@mail.ru

Khanova Ayritta Karimovna, Ph.D. (Candidate of Medicine), Assistant Professor of Internal Medicine Bashkir State Medical University

3, Lenin st., Ufa, Russian Federation

Yavgildina Alfiya Mustamirovna, Ph.D. (Candidate of Medicine), Assistant Professor of Internal Medicine Bashkir State Medical University 3, Lenin st., Ufa, Russian Federation 